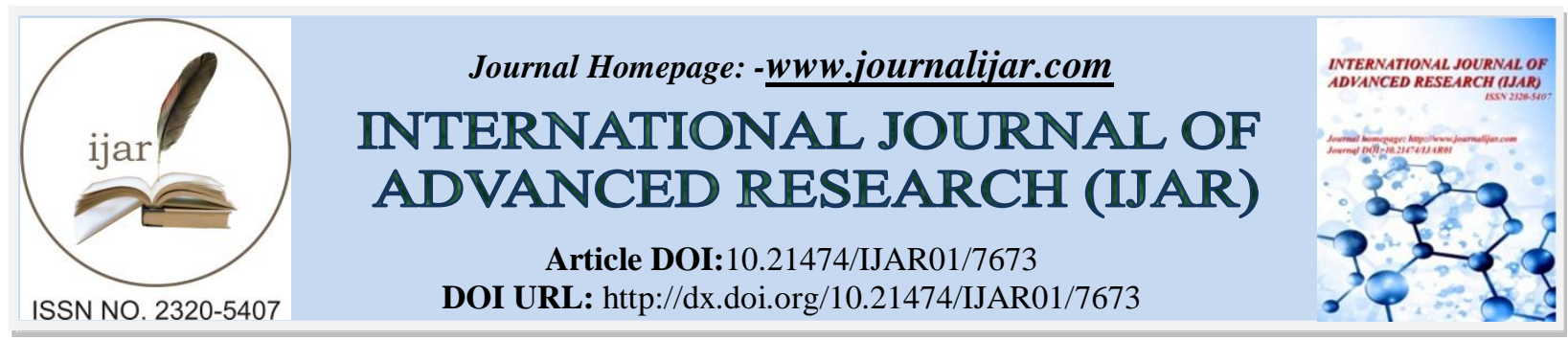

RESEARCH ARTICLE

\title{
BONE MARROW INVOLVEMENT IN NON HAEMATOLOGICAL MALIGNANCIES: A CLINICO- PATHOLOGICAL STUDY FROM A TERTIARY CARE CENTER OF KASMIR VALLEY.
}

\author{
Shareefa Akhter ${ }^{1}$, Subuh Parvez Khan ${ }^{1}$, Sajad Geelani ${ }^{2}$, Shuaeb Bhat ${ }^{1}$, Saleem Hussain ${ }^{1}$, Shazieya Akhter ${ }^{1}$, \\ Noorjahan Ali ${ }^{1}$, Sumayya Shah ${ }^{1}$, Humira Bashir ${ }^{1}$, Javid Rasool ${ }^{2}$ and Fiza Parvez Khan ${ }^{3}$ \\ 1. Department of Haematopathology, Sher e Kashmir Institute of Medical Sciences, Srinagar, J\&K, India. \\ 2. Department of Clinical Haematology Sher e Kashmir Institute of Medical Sciences, Srinagar, J\&K, India. \\ 3. Department of Haematology and Transfusion Medicine, Government Medical College Srinagar J\&K, India.
}

\section{Manuscript Info}

(..........................

Manuscript History

Received: 05 July 2018

Final Accepted: 07 August 2018

Published: September 2018

\section{Abstract}

Introduction: Solid tumors may spread to the Bone Marrow via the hematogenous route. Most common solid tumors which metastasize to marrow in adults are carcinoma of the prostate, breast and lung. In pediatric age group neuroblastoma, rhabdomyosarcoma, Ewing's sarcoma and retinoblastoma are the major tumors metastasizing to BM. The clinical features of these may mimic some of the haematologic disorders, as the patients may present with cytopenias, lymphadenopathy and HepatosplenomegalyAim of this study was to analyse the bone marrow involvement in non haematological malignancies.

Material and methods:This was a retrospective study conducted in the department of haematology ,Sher e Kashmir Institute of Medical Sciences for a period of 5 years from January 2012 to December 2016. In this retrospective study, bone marrow aspiration showing metastases of solid tumors were studied. Basic clinical characteristics of patients and complete blood counts were obtained from the hospital records. Cases having bone marrow infiltration by lymphoma were excluded from the study.

Results:In a period of 5 years, 68 bone marrow aspirations showing metastatic deposits were studied. 40 patients were Males $(58.8 \%)$ and 20 were females $(29.4 \%)$.Age of the cases ranged from 8 months to 80 years with mean age of 49.2 years. 20 cases $(29.5 \%)$ were in paediatric age group. Anemia was seen at presentation in 38 cases $(55.8 \%)$ while thrombocytopenia was seen in 35 cases(51.4\%). Lung cancer andneuroblastoma were the most frequent malignancy metastasising to marrow in adults and paediatric population respectively.

Conclusion:Bone marrow aspiration is an effective method for evaluating solid tumors metastatic to bone marrow. Aspiration of bone marrow provides an easy and quick way of detection of marrow involvement, however, biopsy with immunohistochemical and / or molecular techniques may be needed in case of microscopical tumor metastasis.

Copy Right, IJAR, 2018,. All rights reserved. 


\section{Introduction:-}

Bone marrow examination is one of the most important diagnostic procedure to assess various haematological disorders ${ }^{1}$ Though bone marrow (BM) involvement is most commonlyseen with myeloid or lymphoid hematological malignancies, solid tumors may also spread to the BM via the hematogenous route. Most common solid tumors which metastasize to marrow in adults are carcinoma of the prostate, breast and lung. And in pediatric age group neuroblastoma, rhabdomyosarcoma, Ewing's sarcoma and retinoblastoma are the major tumors metastasizing to $\mathrm{BM}^{2,3}$. The clinical features of these may mimic some of the haematologic disorders, as the patients can present with cytopenias, lymphadenopathy and hepatosplenomegaly. BM examination is done in cases of non hematological malignancies in order to stage the disease or to know the involvement. Detection of the metastasis in bone marrow is very important as it may affect the clinical course, treatment, and overall prognosis of the disease

Aim of this study was to analyse the bone marrow involvement in non haematological malignancies.

\section{Material and methods:-}

This was a retrospective study conducted in the department of haematology ,Sher e Kashmir Institute of Medical Sciences for a period of 5 years from January 2012 to December 2016. In this retrospective study, bone marrow aspiration showing metastases of solid tumors were recorded. Basic clinical characteristics of patients as well as sites of metastases and complete blood counts were obtained from the hospital records. Anemia was defined as Hb value $\leq 10 \mathrm{gm} / \mathrm{dL}$, thrombocytopenia as platelet count below $100,000 / \mathrm{mm} 3$. Statistical analyses were performed using SPSS software version 16.0. Cases having bone marrow infiltration by lymphoma were excluded from the study.

\section{Results:-}

In a period of 5 years, 68 bone marrow aspirations showing metastatic deposits were studied. 40 patients were Males(58.8\%) and 20 were females(29.4\%). Age of the cases ranged from 8 months to 80 years with mean age of 49.2 years. 20 cases $(29.5 \%)$ were in paediatric age group.The distribution of cases in adults and paediateic age group is shown in Table 1 and 2 repectively. Anemia was seen at presentation in 38 cases $(55.8 \%)$ while thrombocytopenia was seen in 35 cases $(51.4 \%)$.

Table 1:-Frequencies of various solid tumors in bone marrow in adult age group

\begin{tabular}{|l|l|l|}
\hline Primary site tumor & Number of cases & Percentage \\
\hline Lung & 15 & $31.2 \%$ \\
\hline Stomach & 08 & $16.6 \%$ \\
\hline Prostate & 05 & $10.4 \%$ \\
\hline Breast & 06 & $12.5 \%$ \\
\hline Small Round Cell Tumor(unclassified) & 05 & $10.4 \%$ \\
\hline Bladder & 02 & $4.1 \%$ \\
\hline Carcinoma of Unknown primary & 03 & $6.25 \%$ \\
\hline Ovary & 02 & $4.1 \%$ \\
\hline Ewings sarcoma & 02 & $4.1 \%$ \\
\hline Total & 48 & $100 \%$ \\
\hline
\end{tabular}

Table 2:-Frequencies of various solid tumors in bone marrow in paediatric age group

\begin{tabular}{|l|l|l|}
\hline Primary site tumor & Number of cases & Percentage \\
\hline Neuroblastoma & 08 & $40 \%$ \\
\hline Wilms Tumor & 03 & $15 \%$ \\
\hline Ewings Sarcoma & 06 & $30 \%$ \\
\hline Retinoblastoma & 02 & $10 \%$ \\
\hline Rhabdomyosarcoma & 01 & $5 \%$ \\
\hline Total & 20 & \\
\hline
\end{tabular}




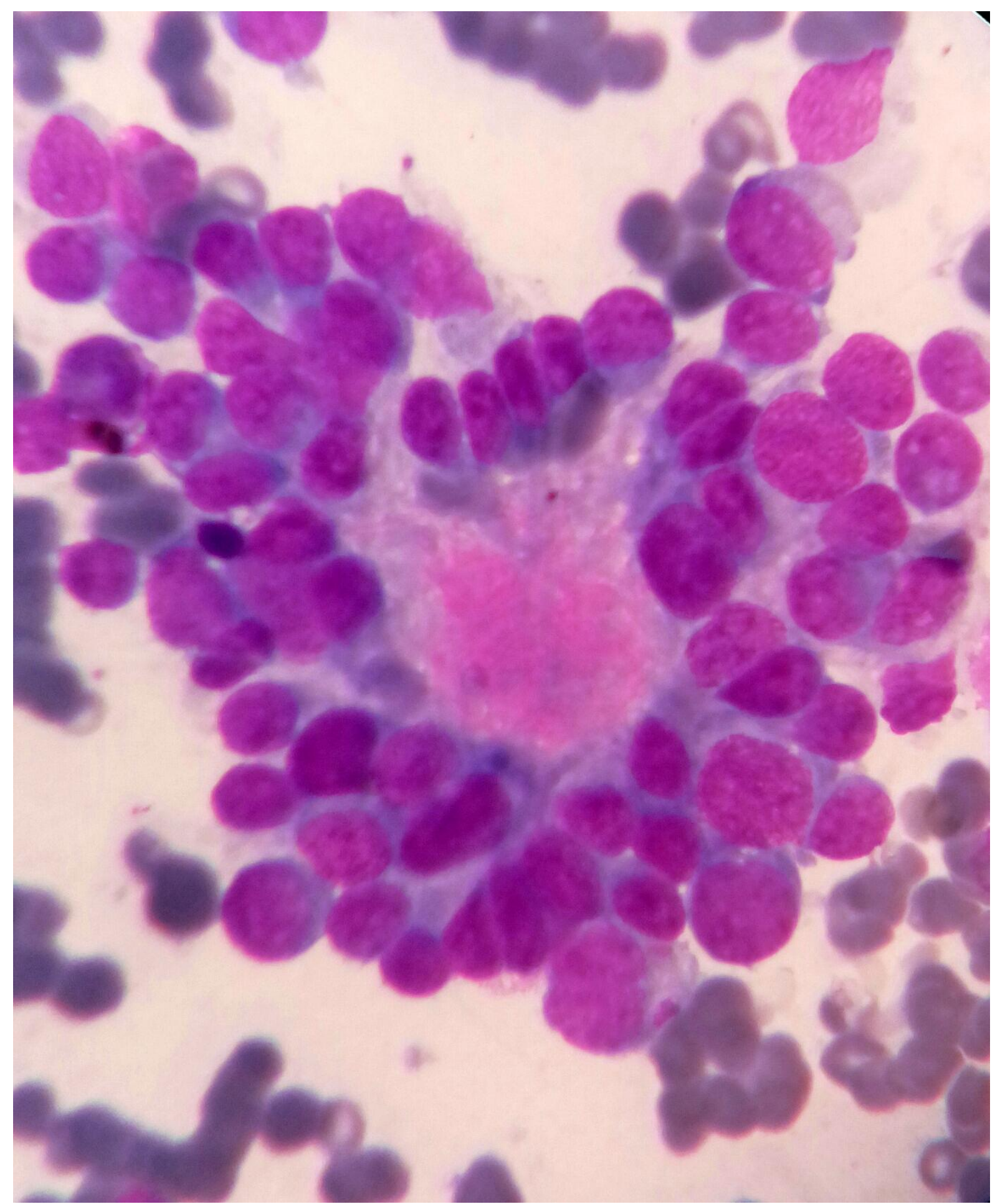

Figure 1:-Neuroblastoma - Photomicrograph showing small round cells with high nuclear cytoplasmic ratio arranged in rosette around central neuropil (100X, Leishmann stain).

\section{Discussion:-}

The present study was conducted for a period of 5 years in which 68 cases presenting with bone marrow metastasis were studied..Age of the cases ranged from 8 months to 80 years with mean age of 49.2 years with male to female ratio of 2:1. Syed NN et $\mathrm{al}^{4}$ conducted a study on non haematological disorders of bone marrow and found predominace of males with male to female ratio of 3.2:1 ratio with mean age of 33 years (range 6 months to 89 years), ${ }_{4}$ In a study conducted by Kilickcap $S$ et al ${ }^{5}$ Mean age was $49 \pm 13$ (min: 17, max: 77). In the present study, 
Anemia was seen at presentation in 38 cases(55.8\%) while thrombocytopenia was seen in 35 cases(51.4\%). Mehdi SR et al $^{6}$ in his study found Anemia the commonest (71.4\%) hematological finding followed by thrombocytopenia in $45.1 \%$ cases.In a study conducted by KilickapS et $\mathrm{al}^{5}, 68.5 \%$ of patients were found to have anemia and $58.9 \%$ thrombocytopenia. At the time of diagnosis.In the present sudy,in the adult age group , the highest number of bone marrow involvement was seen in lung carcinoma accounting for $31.2 \%$ followed by gastric carcinoma accounting for $16.6 \%$. In a similar study conducted by Meenai FJ et al ${ }^{7}$, Maximum number of metastasis to marrow cases were of carcinoma of lung, including both small and non small cell type(27.3\%).Syed NN et al ${ }^{4}$ in their study also found lung carcinoma to be the most frequent metastatic tumor to marrow.KilickapS et $\mathrm{al}^{5}$ in their study found Breast cancer $(28.8 \%)$ and lung cancer $(23.3 \%)$ to be the the most common cancers associated with a BM metastasis, followed by gastric cancer $(9.7 \%)$. DuaS et al ${ }^{8}$ conducted a similar study involving 10 cases in which 6 were adults. Maximum number of cases(3 cases) in the adult group showed metastasis from lung cancer. In the present study, 20 cases $(29.5 \%)$ were in paediatric age group.Neuroblastoma metastasis was seen in majority of cases accounting for $40 \%$ of cases(Figure 1). In study conducted by KilickapS et $\mathrm{al}^{5}$, neuroblastoma metastasis was seen in majority of paediatric cases. Mohanty et al. ${ }^{9}$ conducted a similar study in which all pediatric cases had neuroblastoma. Neuroblastoma was the most common primary tumor in children in a study conducted by Sari R et al. $^{10}$

\section{Conclusion:-}

Bone marrow aspiration is an effective method for evaluating solid tumors metastatic to bone marrow. Aspiration of bone marrow provides an easy and quick way of detectionof marrow involvement, however, biopsy with immunohistochemical and / or molecular techniques may be needed in case of microscopical tumor metastasis.

\section{Bibliography:-}

1. Shaheen N, Khan MQA, Azim W et al. Bone marrow aspiration. The diagnostic tool in haematological and nonhaematological disorders. Pak J Pathol 2010;21(1):1-4

2. Kaur G, Basu S, Kaur P et al . Metastatic bone marrow tumors: Study of nine cases and review of the literature. Journal of Blood Disorder and Transfusion 2011;2:110.

3. Bain BJ, Clark DM, Wilkins BS et al . Metastatic tumors. In: Bain BJ, Clark DM, Wilkins BS, editors. Bone Marrow Pathology. 3rd ed. England, Malden, MA: Blackwell Science, Bon Oxford; 2001. p. 430-61

4. Syed NN,Moiz B, Adil SN et al.Diagnostic importance of bone marrow examination in non-hematological disorders .J Pak Med Assoc.2007; 57(3)

5. Kilickap S, Erman M, Dincer M. Bone marrow metastasis of solid tumors: Clinicopathological evaluation

6. of 73 cases Turkish Journal of Cancer. 2007. 37(3);85

7. Mehdi SR, Bhatt ML. Metastasis of Solid Tumors in Bone Marrow: A Study from Northern India. Indian Journal of Hematology and Blood Transfusion.2011,27, (2,) 93-95

8. Meenai FJ, Ojha $\mathbf{S}^{*}$, Ali MA, et al. Bone Marrow Involvement in Non-Hematological Malignancy: A Clinico-pathological Study From a Tertiary Hospital. Annals of Pathology and Laboratory Medicine,2018. $5(5)$

9. S DUA S, CHHABRA S, GUPTA M et al. MARROW METASTASIS IN SOLID TUMORS: A RETROSPECTIVE STUDYIndianJ.Sci.Res. 7(2) : 79-82, 2017

10. Mohanty SK, Dash S. Bone marrow metastasis in solid tumors. Indian J PatholMicrobiol 2003;46:613-6.

11. Sari R, Aydogdu I, Ozen S, et al. Metastatic bone marrow tumors: a report of six cases and review of the literature. Haematologia 2001;31:215-23. 